\title{
Cancer worry among Norwegian male BRCA1/2 mutation carriers
}

\author{
Nina Strømsvik • Målfrid Råheim • Eva Gjengedal
}

Published online: 21 May 2011

(c) The Author(s) 2011. This article is published with open access at Springerlink.com

\begin{abstract}
This qualitative study explored the experiences of Norwegian men after being identified as BRCA $1 / 2$ mutation-positive. Only limited knowledge is available on this topic; therefore, the aim of this study was to gain a deeper insight from the men's own perspectives. Data were collected from in-depth interviews with 15 men and seven of their partners. The participants described fear of cancer development, and two main narrative patterns were identified: fear for their own health, including fear of developing cancer, and negative feelings about responsibility for others' health. The men expressed fear of developing cancer themselves and described a need for genetic risk information. They were also deeply concerned about how the mutation might affect their children and other relatives. There is a need for guidelines concerning genetic risk information and follow-up programs for male BRCA $1 / 2$ mutation carriers. This study adds valuable contextual insights into their experiences of living with fear of cancer.
\end{abstract}

\footnotetext{
N. Strømsvik ( $\square)$

Western Norway Familial Cancer Center, Haukeland University

Hospital, 5021 Bergen, Norway

e-mail: nina@tbt.no

N. Strømsvik · M. Råheim · E. Gjengedal

Department of Public Health and Primary Health Care,

University of Bergen, Bergen, Norway

N. Strømsvik

Department of Medical Genetics, University Hospital

of North-Norway, 9038 Troms $\varnothing$, Norway

E. Gjengedal

Faculty of Health and Social Care,

Molde University College, 6402 Molde, Norway
}

Keywords Breast and ovarian cancer - Male BRCA 1/2 mutation carriers - Male fear of developing cancer . Men and genetic counselling - Men's health

\section{Introduction}

Following the identification of the BRCA1 and BRCA2 genes, genetic testing has become available to both men and women in families at risk for hereditary breast and ovarian cancer (HBOC). Once the family-specific mutation is known, family members may be identified as carriers or noncarriers. Both male and female offspring of mutation carriers have a $50 \%$ risk of inheriting the cancer-associated mutation. However, the risk of developing cancer is much higher in women than in men who carry the mutation. The lifetime risk of developing breast cancer (BC) is estimated to be between 43 and $95 \%$ for female carriers [1]. They also have up to a $60 \%$ risk of developing ovarian cancer (OC). Variable risk estimates have been reported, depending on whether the studies are family- or case-ascertained. An established risk management program for female BRCA1/2 mutation carriers is available in Norway [2]. Men may also be identified as mutation carriers, but the implications for BRCA1/2-positive men are still somewhat unclear. Male BRCA1/2 carriers' risk of developing prostate cancer (PRCA) is estimated to be 6-14\%, and BRCA2 mutation-positive men have an additional $6 \%$ risk of developing $\mathrm{BC}[1,3]$. In addition, the risks of pancreatic, gastric and hematologic cancers have also been reported to be higher in BRCA carriers than in noncarriers [4]. There are conflicting data regarding the risk of colorectal cancer and melanoma [4]. New research has also suggested that BRCA1/2 mutation carriers may develop a more aggressive form of PRCA [5, 6], and a more rapid progression of PRCA in men with BRCA2 mutations has 
been reported [7]. It is thought that target screening to detect cancer at an early clinical stage may be beneficial for these men [5, 7]. However, risk management and counselling strategies are still lacking [4].

Little research attention has been paid to male experiences in HBOC families [8]. The sparse literature available describes men as mainly seeking genetic testing out of an obligation to their children [9-13], and it is reported that women have a strong influence upon male decision-making regarding genetic testing [11]. Previous evidence has described the wives as responsible for revealing genetic risk information in the family [12] and men as finding it difficult to share unfavourable test results with their children [12, 14-16]. Fear of developing cancer has also been reported among men in HBOC families [10, 15-17], and avoidance is said to be a coping strategy among these men $[15,17]$.

The available studies regarding male experiences in HBOC families report low rates of mutation carriers [8, 9, $11,14]$. As such, limited knowledge regarding the experiences of BRCA1/2 mutation-positive men is available. The aim of this study was to gain a deeper understanding of male BRCA1/2 mutation carriers' experiences. This understanding may contribute to providing optimal care for men in HBOC families who seek genetic counselling and testing.

\section{Methods}

Sample

A letter of invitation was sent from two regional medical genetics departments in Norway to 43 male BRCA1/2 mutation carriers in 19 families. The men were also invited to include their current partners. In accordance with Norwegian legislation, the men had attended genetic counselling both prior to testing and at the time the test results were disclosed. They had not been offered any genetic counselling after the disclosure of their test results, and none of the participants were enrolled in follow-up programs at the time of the interviews.

\section{Data collection and ethical issues}

After approval by the Regional Research Ethics Committee and Norwegian Social Sciences Data Services, data were collected during two separate, in-depth interviews with a minimum of 2 weeks between the interviews. The first interview involved the men only. To obtain knowledge about male-female communication and family dynamics, the men's current partners were invited to participate in the second interview. The participating partners returned a separate consent form. In cases where no partner was participating, two separate interviews were performed with the man. For practical reasons, one man was not able to participate in the second interview. The participants were offered a new genetic counselling session shortly after the interviews were completed, and ten men accepted this offer.

All the interviews were performed face to face and were tape-recorded with consent. They lasted $40 \mathrm{~min}$ on average and occurred in a hospital ward or other location according to the participants' preferences. Initially, an interview guide with broad, key questions was used to explore the subjects' experiences with cancer in their families, male identity, and thoughts about future follow-up programs. They were also asked about how the genetic testing was initiated and their experience with the genetic counselling and testing process. In addition, the respondents were encouraged to expound on issues important to them. In most cases, a long narrative story was generated by initially asking the participants to tell how they became aware of the family mutation and their decision to perform genetic testing. Their stories often started when they learned about the mutation from family members and continued through the process of genetic counselling and testing.

Analysis

Initially, the interviews were analysed using Giorgi's phenomenological approach. He describes four steps in his analysis [18, 19]. First, it was important to get a sense of the entire material by listening through the audiotapes and repeatedly reading the transcripts. Then, meaning units were identified. In the third step, the colloquial language in each meaning unit was transformed into professional terminology. Finally, all the transformed meaning units were considered when they were synthesised into a condensed description structured in themes describing the men's experiences. The first interviews were listened through carefully prior to the second interview, and both interviews were analysed simultaneously to explore the specific context of their stories. Next, core themes were identified across the participants' stories. The data program Nonnumerical Unstructured Data Indexing, Searching, and Theorising (NUDIST) was used to organise and analyse the interview transcripts.

Four core themes were identified, and three of these have been presented elsewhere [20]. The fourth core theme, which concerns fear of cancer development, is presented in this report. This core theme was identified early in the interviews, and most of the participants returned to this issue several times. As this core theme is the main finding in the study, a narrative approach was utilised in the analysis to gain a deeper contextual insight. This methodology makes it 
possible to focus on the participant's specific story and variations between stories [21]. Individuals may organise non-systematic encounters into coherent stories to create meaning from experience [22] or to describe human experience [23]. By following each participant's storyline, we were able to describe how the present is coloured by past experiences and expectations of the future. Simultaneously, as we are able to understand the individual stories in context, we were also to recognise patterns in spite of variations. A narrative story has been described as a meaningful whole containing a beginning, middle and an end [24]. Hence, we listened to the interviews through focusing on this core theme as a story, according to the abovementioned time structure.

\section{Results}

15 male mutation carriers from 12 families and seven of their female partners participated in this study. The men ranged in age from 26 to 73 (median $=51$ ). Three men had no current partners, eight had biological daughters, and one had no children. The interviews were conducted between 2 and 8 years after the disclosure of their test results, and one of the participants had developed prostate cancer.

In most cases a narrative story was generated by initially asking the participants to tell how they became aware of the family mutation and about their decision to undergo genetic testing. The stories of fearing cancer development began when the participants learned about the family mutation. In the middle, they described the process of genetic counselling and testing, as well as their emotional reactions. Finally, they described their situation at the time of the interviews. Two main narrative patterns, both characterised by fear, were identified across the stories: fear for one's own health and fear for and negative feelings of being responsible for others' health. Two different stories, representing typical features of the respondents, were chosen to present the patterns. These two stories stand out by their richness and clarity, and they stimulated us to recognise patterns in spite of variations. Both patterns are present in the participants' stories. To describe variations in the material, a brief sketch and some excerpts from the other participants' experiences follow each story.

\section{Fear for one's own health}

"Bill" is a man in his fifties, with several children and he has recently become a grandfather. He also has several siblings, and an elderly mother. His father and several male and female relatives have died of cancer. He has a very busy work situation, and the interviews took place in his hectic work environments. Bill participated alone in both interviews as his wife did not want participate in the study. He expressed himself very openly and directly during the two interviews, and he had obviously made many reflections regarding his mutation status. His story began when he learned about the family mutation from a distant female relative. Bill did not know how she had become aware of the family mutation. He spent some time evaluating the situation before he decided to approach genetic testing, and he had not involved his children in his decision-making process prior to the genetic test. During the genetic counselling and testing process, he learned that he was mutation-positive, whereas all his siblings turned out to be negative. Bill explained that the knowledge of his mutation status led to a change in his life. The information has made him more anxious about the condition of his health and his cancer risk. He was told that the mutation mainly had consequences for females, information he did not take at face value. On the contrary, Bill questions whether the existing knowledge regarding males' risk may be too scarce and adds that the future may change such information:

... there must be something that researchers haven't yet found. I feel that in ten years' time, a completely different conversation between the health care provider and the mutation carrier will take place. I felt that when I got the news about that gene, that there must be something that happens with men too. It is too good to be true that the cancer risk mainly concerns women.

At the present, Bill feels that the knowledge about his mutation status has made a change in his life, as he has started to worry about the condition of his health and his cancer risk. In addition, some of his friends have recently developed cancer, and he points out that when something happens to people he knows, it has an emotional impact on himself as well, increasing his own cancer fear. He has noticed what he interprets as possible cancer symptoms but has not informed his doctor about his mutation status. He also feels that his heart may be failing, and he suffers from frightening symptoms:

... I've had a few strange things with my heart. They have checked it, but they didn't find anything. They say that I am $100 \%$ healthy. I keep having these strange muscle pains close to my heart, and that makes me anxious. When the anxiety comes, I start feeling anxious about everything else too in some way.

His doctor has prescribed anti-anxiety medication, a situation Bill finds humiliating. No new appointment has been made with his doctor.

All his siblings turned out to be mutation-negative, and Bill feels that they have not shown particular interest in 
him since the disclosure of their test results. He has not informed his children about the family mutation, and at the present, he feels quite lonely. Bill has not discussed his mutation status and his emotional reactions with anyone else except from his wife. He considers discussing health issues or emotional reactions with male friends or relatives as difficult. He now suspects that his father's cancer was caused by the family mutation, which he also connects to a birth defect in one of his children, although none of his children have undergone genetic testing.

\section{Variation}

The participants learned about the family mutation from close or distant relatives. In some cases, the mutation was revealed when close family members developed cancer. Many expressed that they experienced emotional reactions some time after receiving their test results and had felt a need for emotional and informative support some time after the disclosure of their mutation status:

Would have liked to have had a telephone number or a contact person, for when some time has passed and then call up and talk about how things are...

Another participant expressed his feelings of being left alone after the genetic testing:

And then it's like... where can you get....and then

you are like, finished (with the counselling process).

If you were a woman then...

The disclosure of the participants' unfavourable test results led to many questions regarding their own cancer risk. Because they had learned about increased prostate cancer risk, observing the color of their urine and focusing on the frequency of urination was described. Other participants did not worry on a daily basis, but a variety of symptoms made them strongly aware of their mutation status. On one hand, they expressed feelings of relief at not being female; on the other, they envied the fact that women would be entitled to follow-up programs. Some described feeling jealous when others had extensive health checkups. The participants associated other diseases and disabilities with the family mutation and seemed to connect all familial cancer to the family mutation. However, they did experience that mutation-negative family members also developed cancer:

My father also had another brother who did not carry the mutation, but he had colon and lung cancer and died from that even though he didn't have the mutation. That says to me, ok, you don't have to have the mutation to get sick. I won't say that it makes me, I feel sorry that he is dead now, but it is good to know he didn't have the mutation. That feels like something remotely positive.

Most participants questioned their potential risk during the interviews and wanted to receive information on a regular basis, as they expected knowledge to increase in the future.

Fear and bad feelings of being responsible for others' health

"Stuart," an elderly man, participated alone in the two separate interviews. His wife did not want to participate in the study. Initially he expressed an unmet need of information, and was admitted to future genetic counselling after completion of the interviews. In the first interview Stuart seemed a little anxious, but in the second interview 3 weeks later he seemed to be more comfortable with the interview situation. During both interviews he mainly focused on his daughters' cancer risk, and constantly returned to this issue even when other issues were explored.

Stuart comes from a large family and has many siblings, several children and many grandchildren. He suffered the loss of his mother from cancer when he was a teenager:

Yes, I was about fifteen-sixteen years old. We were many siblings, and I was not the oldest, several were younger than me, and the youngest was six or seven years old.

His grand-mother and several other female relatives also died from cancer. He learned about the family mutation when one of his daughters developed cancer at a young age:

She called. We heard that she had a lump and that she had had it removed, taken the test then and when the result came, then she knew. Yes, that's how we found out. And of course, that was a shock.

Stuart's wife and daughter informed both close and distant relatives about the family mutation immediately after they learned about their daughter's mutation status. Stuart and some of his siblings approached genetic counselling and testing together. He described how they travelled together and supported one another when they went to see a genetic counsellor.

During the genetic counselling and testing process, Stuart learned the difficult truth that he had passed on the mutation to several of his daughters. He started to worry about his daughters' cancer risk and is at present still focusing on his daughters' health, hoping that they will do everything possible to reduce their risk. His wife is involved in their daughters' decision-making regarding genetic testing and prophylactic surgery, but he is usually 
not included in these discussions. Stuart is in need of information regarding his daughters' actual risks and risk reduction options but does not know where to address these questions. He finds it difficult to discuss his daughters' actual risks with his wife. Stuart also questions his daughters' reproductive decision-making and worries that they may develop cancer before they undergo prophylactic surgery. One of his daughters is in her midst thirties and has no children, and has expressed that she feels that she is keeping her ovaries on "overtime."

Several of his siblings were also identified as mutation positive, and some younger children in the extended family developed different types of cancer in their childhood. Stuart worries that his grandchildren also may be at risk due to the family mutation. He sees the future of his daughters and grandchildren as unsafe and unpredictable. Stuart has noticed prostate problems and has tried to discuss his mutation status and potential risk with his doctor, who has revealed scarce knowledge about this issue. Stuart feels left quite alone with his questions.

\section{Variation}

Most participants expressed concern for their children as their main motivation for testing, and they described reacting emotionally when they learned about their mutation status:

Yes, then you get those thoughts that you hope it won't, that my children, that you have been so lucky that they didn't get it since they had kids with people outside the family. So, it is a downer, there is no doubt about that.

The participants described being deeply concerned about their sisters and daughters, and feelings of guilt were expressed, especially in relation to daughters. Some had closely followed their daughters' genetic counselling and testing process:

She was pretty quick to take action and took the test. It was a tense time, it was almost like getting the results back from an exam you thought you struggled with.

Some of the participants' mothers had developed cancer, and the men were worried about their mothers' future. Concern for how this risk information would affect their siblings was also expressed. They felt a sense of responsibility towards those family members (especially brothers) who they knew would have difficulties in coping with an unfavourable test result. They also described their concern for family members who did not want genetic testing or did not communicate the risk information to their offspring.

\section{Discussion}

The participants in the present study expressed fears of developing cancer and a need for genetic risk information. Feelings of responsibility for other family members' health were also described, accompanied by feelings of guilt. None of the participants had been offered additional genetic counselling after the disclosure of their test results, and they expressed a need for updated genetic risk information. The participants questioned if the existing risk information was trustworthy or if new information about male risk might be revealed in the future. Many of the men described observing their urine on a daily basis, and some had noticed prostate problems.

Little is known about BRCA1/2-positive males, and the few available studies regarding men in HBOC families have reported low rates of male participation among mutation carriers [8]. Two studies have reported that the motivation for genetic testing among men in HBOC families was fear of cancer or worries about their own health $[15,16]$, and only one study has focused solely on BRCA1/ 2 mutation-positive men [10]. In contrast, another study has reported low levels of cancer fear among males testing for BRCA1/2 [13]. Evidence suggests that cancer amongst their family members may influence men's feelings of risk [15], and the loss of close female relatives causes intrusive feelings of unresolved grief among men in HBOC families [10, 15-17]. However, it has been found that most men with unaffected mothers in HBOC families also viewed themselves as being at increased risk [10].

None of the participants were included in surveillance programs at the time of the interviews, and they experienced their future as unsafe and unpredictable. According to Antonovsky [25], it is important to have some influence on one's own future and fate to experience life as meaningful, which is the main dimension in Antonovsky's sense of coherence (SOC) model. SOC is related to quality of life and perceived health, and it develops throughout one's life [26]. One of the constituents of this model is comprehensibility, which refers to whether experiences are perceived as structured, predictable, and explainable. This is considered important in coping with health-related issues. Coping strategies may have a significant impact on psychological and physical health among persons at risk [27]. Knowledge about male risk and risk reduction options may be crucial for enhancing comprehensibility. Bill clearly expressed that he did not have sufficient information, and he suspected that different risk information would be revealed in the future. The insufficient information seemed to make him less able to deal with his situation. Another component of Antonovsky's theory is manageability, which requires individuals' ability to perceive available resources. From Bill's story, we learned that most 
participants experienced a lack of confidence in their general practitioners (GP). Bill did not inform his doctor about his mutation status, despite suffering from what he interpreted as possible cancer symptoms. This lack of trust may have prevented the men from regarding their general practitioners' as available resources. Their reluctance to discuss genetic information with their local GPs may also be due to fear of being stigmatised [20]. Additionally, men have been described as less able to communicate their BRCA1/2 test results compared to women [28]. The men's lack of confidence in their GPs due to doctors' lack of genetic knowledge is consistent with findings amongst women in HBOC families [29]. However, in contrast to males, BRCA1/2 mutation-positive females are included in risk management programs.

The participants described feeling responsible for the health of other family members. Anxiety about passing on a genetic condition to children has also been described in other studies $[12,17,30]$. Most of the participants claimed that they underwent the genetic test out of concern for their children. This reasoning is consistent with other studies [913]. We learned from Stuart's story that he is concerned about his daughters' cancer risk and is in need of information regarding their actual risks and risk reduction options. According to Antonovsky's theory [25], this information is necessary to enhance comprehensibility when, for instance, illness or increased risk of illness strikes. Stuart also reported that his wife is involved in discussions with his daughters regarding risk reduction options, but he is not included in these discussions. He feels that the future is unsafe and unpredictable for his daughters and grandchildren. According to the SOC model, it is essential to have some influence on fate to experience the actual situation as meaningful [25]. It has also been shown in previous studies that men in HBOC families may be excluded from family conversations about female cancer [15] and that few males participate in female conversations about prophylactic surgery [10]. The men in this study also expressed concerns about relatives who they felt would be unable to cope with unfavourable test results; this concern has also been reported for women [29].

The male counselling and genetic testing process is often initiated by female relatives [10], and it is possible that the men may not have been aware of their own potential cancer risk prior to this process. It has been found that introducing future risk information about diseases may be harmful and can lead to insecurity [31-33]. Evidence suggests that mutation carriers should be counselled about issues such as lifestyle and self-examination techniques. The increased risk of other malignancies should also be discussed with male mutation carriers [4]. However, this discussion might increase their fear of developing cancer if no management strategies are available. The emotional impact of genetic risk information has been described as depending on the possibility of having any control over the course of the genetic condition [30], which is in accordance with the manageability component of the SOC model. In accordance with studies reporting men's interest in support groups and need of additional genetic counselling after predictive testing for BRCA1/2 [10,34], many participants accepted the offer of future genetic counselling after completion of the interviews.

\section{Methodological considerations}

One important way for individuals to make sense of and give meaning to individuals is to organise experiences into a narrative form [35]. In this case, the narrative stories contributed to the participants' understanding of their own experiences as BRCA1/2 mutation carriers. The study of the participants' responses as narratives and the effort to empower these men are therefore closely related [35]. The interviews were conducted by the first author, who is a professional genetic counsellor with long-standing experience in cancer counselling. This experience may have enhanced the communication with the participants. The participation rate in the study was low, and it is a possibility that only men with strong cancer worries participated in the study. However, other studies have also reported low rates of male participation among mutation carriers [8]. Further investigations of male cancer worry among BRCA1/2 mutation carriers should be conducted in other populations, using both qualitative and quantitative study designs.

\section{Conclusions}

The results of this study indicated that there is a need for guidelines concerning genetic counselling, risk information and follow-up programs for male BRCA1/2 carriers. Information about risk reduction options and surveillance programs for women should also be included in genetic counselling sessions for men.

Open Access This article is distributed under the terms of the Creative Commons Attribution Noncommercial License which permits any noncommercial use, distribution, and reproduction in any medium, provided the original author(s) and source are credited.

\section{References}

1. Levy-Lahad E, Friedman E (2007) Cancer risks among BRCA1 and BRCA2 mutation carriers. Br J Cancer 96(1):11-15

2. Møller P (2006) Diagnostikk og behandling av arvelig bryst-og eggstokkreft. Konsensusforslag NGAK, NBCG, NFGO verdr Tiltak ved arvelig bryst-og eggstokkreft 
3. Lux MP, Fasching PA, Beckmann MW (2006) Hereditary breast and ovarian cancer: review and future perspectives. J Mol Med 84(1):16-28

4. Mohamad HB, Apffelstaedt JP (2008) Counseling for male BRCA mutation carriers: a review. Breast 17(5):441-450

5. Mitra A, Fisher C, Foster CS et al (2008) Prostate cancer in male BRCA1 and BRCA2 mutation carriers has a more aggressive phenotype. Br J Cancer 98(2):502-507

6. Mitra AV, Bancroft EK, Barbachano Y et al (2010) Targeted prostate cancer screening in men with mutations in BRCA1 and BRCA2 detects aggressive prostate cancer: preliminary analysis of the results of the IMPACT study. BJU Int 107(1):28-39

7. Narod SA, Neuhausen S, Vichodez G et al (2008) Rapid progression of prostate cancer in men with a BRCA2 mutation. Br J Cancer 99(2):371-374

8. Stromsvik N, Raheim M, Oyen N, Gjengedal E (2009) Men in the women's world of hereditary breast and ovarian cancer-a systematic review. Fam Cancer 8(3):221-229

9. Hallowell N, Arden-Jones A, Eeles R et al (2006) Guilt, blame and responsibility: men's understanding of their role in the transmission of BRCA1/2 mutations within their family. Sociol Health Illn 28(7):969-988

10. Liede A, Metcalfe K, Hanna D et al (2000) Evaluation of the needs of male carriers of mutations in BRCA1 or BRCA2 who have undergone genetic counseling. Am J Hum Genet 67(6): 1494-1504

11. Hallowell N, Ardern-Jones A, Eeles R et al (2005) Men's decision-making about predictive BRCA1/2 testing: the role of family. J Genet Couns 14(3):207-217

12. d'Agincourt-Canning L (2001) Experiences of genetic risk: disclosure and the gendering of responsibility. Bioethics 15(3): 231-247

13. Lodder L, Frets PG, Trijsburg RW et al (2001) Men at risk of being a mutation carrier for hereditary breast/ovarian cancer: an exploration of attitudes and psychological functioning during genetic testing. Eur J Hum Genet 9(7):492-500

14. Hallowell N, Ardern-Jones A, Eeles R et al (2005) Communication about genetic testing in families of male BRCA1/2 carriers and non-carriers: patterns, priorities and problems. Clin Genet 67(6):492-502

15. McAllister MF, Evans DG, Ormiston W, Daly P (1998) Men in breast cancer families: a preliminary qualitative study of awareness and experience. J Med Genet 35(9):739-744

16. Daly PA, Nolan C, Green A et al (2003) Predictive testing for BRCA1 and 2 mutations: a male contribution. Ann Oncol 14(4): 549-553

17. Dudok de Wit AC, Tibben A, Frets PG, Meijers-Heijboer EJ, Devilee P, Niermeijer MF (1996) Males at-risk for the BRCA1 gene, the psychological impact. Psychooncology 5:251-257

18. Giorgi A (1985) Phenomeology and psychological research. Duquesne University Press, Pittsburgh
19. Giorgi A (2009) The descriptive phenomenological method in psychology: a modified Husserlian approach. Duquesne University Press, Pittsburgh

20. Stromsvik N, Raheim M, Oyen N, Engebretsen LF, Gjengedal E (2010) Stigmatization and male identity: Norwegian males' experience after identification as BRCA1/2 mutation carriers. J Genet Couns 19(4):360-370

21. Benner P (1994) Interpretive phenomenology. Sage Publication, California

22. Chamberlain K, Stephens C, Lyons AC (1997) Encompassing experience: meanings and methods in health psychology. Psychol Health 12:691-709

23. Polkinghorne DE (1995) Narrative configuration in qualitative analysis. In: Hatch JA, Wisniewski R (eds) Life history and narrative. The Falmer Press, London, pp 5-24

24. Reissman CK (1993) Narrative analysis. Sage Publications, London

25. Antonovsky A (1987) The mystery of health: how people manage stress and stay well. Jossey bass, San Francisco

26. Lindstrom B, Eriksson M (2005) Salutogenesis. J Epidemiol Community Health 59(6):440-442

27. Glanz K, Rimer BK, Lewis FM (2002) Health behavior and health education theory, research, and practice. 3rd edn. JosseyBass, San Francisco

28. Finlay E, Stopfer JE, Burlingame E et al (2008) Factors determining dissemination of results and uptake of genetic testing in families with known BRCA1/2 mutations. Genet Test 12(1):81-91

29. MacDonald DJ, Sarna L, Weitzel JN, Ferrell B (2010) Women's perceptions of the personal and family impact of genetic cancer risk assessment: focus group findings. J Genet Couns 19(2):148-160

30. McAllister M, Davies L, Payne K, Nicholls S, Donnai D, MacLeod R (2007) The emotional effects of genetic diseases: implications for clinical genetics. Am J Med Genet A 143A(22): 2651-2661

31. Getz L, Nilsson PM, Hetlevik I (2003) A matter of heart: the general practitioner consultation in an evidence-based world. Scand J Prim Health Care 21(1):3-9

32. Kavanagh AM, Broom DH (1998) Embodied risk: my body, myself? Soc Sci Med 46(3):437-444

33. Getz L, Kirkengen AL, Hetlevik I, Romundstad S, Sigurdsson JA (2004) Ethical dilemmas arising from implementation of the European guidelines on cardiovascular disease prevention in clinical practice. A descriptive epidemiological study. Scand J Prim Health Care 22(4):202-208

34. Stroup AM, Smith KR (2007) Familial effects of BRCA1 genetic mutation testing: changes in perceived family functioning. Cancer Epidemiol Biomarkers Prev 16(1):135-141

35. Mishler CG (1986) Research interviewing. Context and narrative. Harvard University Press, Cambrigde 